\title{
Frictional Heating in Railway Brakes: A Review of Numerical Models
}

\author{
Piotr Wasilewski ${ }^{1,2}$
}

Received: 18 April 2018/ Accepted: 15 November 2018/Published online: 26 November 2018

(C) The Author(s) 2018

\begin{abstract}
In the design process of a railway vehicle it is crucial to determine the operating temperature of the brake friction elements. The thermal load related to braking depends on both the design of the vehicle and its braking system but also on the operating conditions in service. It is therefore justified to model frictional heating of the friction elements in the design phase. As railway braking differs substantially from automotive or aircraft braking, current review article is focused on the published literature concerning specifically modelling of railway tread and disc brakes. However, to present the complete picture of the state-of-the-art, studies undertaking related topics concerning frictional heating are also discussed. It is concluded that the existing models should be further developed to account for mutual coupling of operation conditions and the coefficient of friction.
\end{abstract}

\section{Introduction}

Friction brake in railway vehicles is used to reduce their speed, maintain it while negotiating a descent or to keep the vehicle stationary. The physical phenomenon behind it is friction force generated at the interface of two bodies sliding against each other. Transformation of mechanical energy into heat in the course of brake application leads to increase in the temperature of the friction elements of a brake (friction pair).

Braking performance required for the railway vehicle is among the most important criterions in choosing type of the braking system. Two most common types of friction brakes used currently in railway vehicles are tread brake and disc brake. In tread brakes the friction pair consists of the wheel and the brake shoe. Disc brakes comprise brake disc (which is in most cases either wheel-mounted or axlemounted) and brake pads. Thermal load, which the friction pair will be subject to in operation, is a key issue when designing braking systems and selecting the materials from which friction elements will be manufactured. Depending

Piotr Wasilewski

pwasilewski@frenoplast.pl

1 Faculty of Mechanical Engineering, Bialystok University of Technology (BUT), 45C Wiejska Street, 15-351 Białystok, Poland

2 SMiOC Frenoplast Bułhak i Cieślawski S.A, Korpele 75 Strefa, 12-100 Szczytno, Poland on the estimated temperature reached by the disc brake, a cast iron, cast steel or steel disc and suitable composite brake pads, organic or sintered, may be used. In tread brakes, cast iron brake shoes, which were used almost from the beginning of the development of railway technology, are gradually superseded by composite brake shoes-organic and sintered [39]. The limiting factor in application of tread brakes is the fact that wheel is one of the friction elements and simultaneously constitutes running gear. Therefore, the consequences of its failure due to excessive thermal load may be far more serious than in disc brakes. In the course of railway vehicles design process, selection of friction materials is verified by tests on a full-scale dynamometer which simulates the actual operating conditions of the vehicle. The characteristics of the friction pair under specific operating conditions are then analysed, e.g. the dependency of the coefficient of friction and wear of the friction elements on temperature. The condition of the friction pair is also assessed-the desirable feature of the materials is that they are not subject to thermal degradation or destruction under given operating conditions.

Friction materials are also tested in the reduced scale. The disadvantage of this method is that it is not possible to simultaneously represtent all operating conditions and the geometric relations of the friction elements [16, 2]. Pinon-disc tribometers are also used to test friction materials used in railway brakes $[1,32]$.

As the full-scale dynamometer testing is time-consuming and costly, it seems beneficial to apply simulation 
methods and use bench tests only to validate the design before proceeding to the prototype production phase.

In the course of braking, in particular during drag or emergency brake application as well as consecutive brake applications with relatively short cooling period, the friction pair is subject to considerable thermal load. Day et al. indicate two types of the effect of thermal load on friction pair: (1) bulk thermal effects, such as deformation (e.g. brake disc coning), and (2) localised thermal effects, such as heat spots or cracks [14] . The mechanical and thermal stresses as well as local overheating resulting from frictional heating in the course of brake application lead to changes in the material structure, cracks and other damage which have negative influence on the life-span of the friction pair. As the requirements concerning durability, reliability and, above all, safety of railway vehicles are more and more demanding, it is crucial to determine thermal loads which friction pair will be subject to under the designed operating conditions. The first step to conduct such an analysis is to calculate the temperature field evolution. This subject was undertaken by researchers already in the 1960s [10, 5] and is still quite current $[6,9,20,25,26,30,45,5-55,57,60,61]$.

When analysing frictional heating, the researchers employ analytical methods which provide exact solutions to the given problems $[10,11,19,25,33,57,58]$. Analytical methods have however their limitations and often require simplifications. More complex problems are analysed with numerical methods, in particular with finite elements (FEs) method, which is subject of the review presented in this paper.

\section{Temperature Calculations in Railway Tread Brake}

Although disc brake has many advantages over tread brake (which is discussed in more detail in Sect. 3), tread brake is still a very common technical solution, in particular in freight wagons and in railway vehicles where space in the bogies design is very limited, e.g. motor bogies of railway vehicles used in underground transportation (metro rolling stock).

Important advantages of tread brake are: relatively simple design and its reliability. In a typical railway brake, mechanical force is generated by the pressurised air in the brake cylinder. In tread brake the piston force is multiplied by the lever mechanism (brake rigging) and presses, through the brake block, a brake shoe to the wheel's running surface. Friction force is generated as a result of the wheel-brake shoe contact. Wheel and brake shoe are worn in the process.
One of the key factors that contributed to the development of composite brake shoes in Europe was the attempt to reduce the rolling noise, which is strictly related to the roughness of the wheel running surface $[15,38]$. For tread braked wheels, a crucial factor is the brake shoe material. Composite brake shoes are known to generate less rough surface $[15,28]$ and experimental results show that their tendency to form hot spots is weaker in comparison to cast iron [38]. Due to lower thermal conductivity of composite brake shoes, as compared to cast iron brake shoes, the amount of heat that is absorbed by tread braked wheels equipped with composite brake shoes is higher than wheels braked by cast iron brake shoes [51].

The significance of the brake shoe material properties on thermal load which wheel is subject to during braking is accounted for in the UIC (Union Internationale des Chemins de fer-International Union of Railways) homologation procedure for composite brake shoes. Test programme no. A6 is a simulation of brake failure-a scenario where normal force is exerted on the brake shoe while the vehicle travels at a constant velocity. The result of the test is deemed positive when the average temperature measured under the wheel rolling surface does not exceed specified value in defined time or the linear wear of the brake shoe reaches a certain value [48]. These requirements stem from the concept that in case of unusually high thermal load, the brake shoe should act as a "fuse" protecting the wheel-after exceeding certain temperature, a sudden increase in brake shoe wear should preferably occur. This in consequence reduces the amount of heat transferred to the wheel.

The fact that the safe operation of a railway wheel of a given design depends, among other factors, on how the thermal load results in mechanical stress is reflected in the standard issued by the Association of American Railroads (AAR) [3]. This document presents input data for standardised wheel stress analysis accounting also for the thermal load which wheel is subject to in operation.

Considering the significance of temperature prediction in railway tread braking, studies focused on modelling of frictional heating in tread brakes are discussed.

Petersson created a two-dimensional finite element (FE) model of the railway tread brake equipped with a single composite brake shoe $(250 \mathrm{~mm}$ long, $80 \mathrm{~mm}$ wide and $40 \mathrm{~mm}$ thick) [37]. In order to stabilise the solution, streamline diffusion method was employed. The case under study was a drag brake application at constant velocity of $80 \mathrm{~km} / \mathrm{h}$, while the normal force exerted on the brake shoe was $4000 \mathrm{~N}$. The brake application lasted $300 \mathrm{~s}$. The heat generated on the brake shoe-wheel interface was defined as:

$q_{\text {in }}=\mu p V$ 
where $q$-heat flow, $\mu-$ coefficient of friction, $p-$ contact pressure, $V$-sliding velocity.

It was assumed that the coefficient of friction $\mu$ has a constant value of 0.20 . The frictional heat was divided between wheel and the brake shoe using the equations below:

$q_{\mathrm{w}}=\frac{T_{\mathrm{b}}-T_{\mathrm{w}}}{r_{\mathrm{w}}+r_{\mathrm{b}}} p+\frac{r_{\mathrm{b}}}{r_{\mathrm{w}}+r_{\mathrm{b}}} q_{\mathrm{in}}$

$q_{\mathrm{b}}=\frac{T_{\mathrm{w}}-T_{\mathrm{b}}}{r_{\mathrm{w}}+r_{\mathrm{b}}} p+\frac{r_{\mathrm{w}}}{r_{\mathrm{w}}+r_{\mathrm{b}}} q_{\mathrm{in}}$

where $q$-heat flow, $T$-temperature, $r$-thermal contact resistance constant $\left(\mathrm{N}{ }^{\circ} \mathrm{C} / \mathrm{W}\right), p$-contact pressure, and subscripts $\mathrm{b}$ and $\mathrm{w}$ denoting brake shoe and wheel respectively.

In order to define a reference case for further analysis, the model was calibrated with the experimental data, i.e. temperature values measured in the course of the full-scale dynamometer test. In the next step the sensitivity study was carried out. The author investigated the influence of the heat partition, contact pressure distrbution and specific heat capacity of the brake shoe on the calculated temperature fields.

The heat partition was modified in two ways: (1) by varying the ratio of thermal contact resistance constants while keeping their sum constant and (2) by varying the sum of thermal contact resistance constants while keeping their ratio constant. As expected, increase in $\frac{r_{\mathrm{b}}}{r_{\mathrm{w}}}$ quotient leads to the increase in wheel temperature and increase in $r_{\mathrm{b}}+r_{\mathrm{w}}$ sum results in decrease of wheel temperature.

Three cases of circumferential contact pressure distribution on the wheel-brake shoe interface were analysed, namely sinusoidal, linear and constant pressure distribution. It was concluded that the best corellation with the temperature fields measured experimentally was obtained for the sinusoidal pressure distribution.

Specific heat capacity of the brake shoe in the reference case was $1000 \mathrm{~J} / \mathrm{kg}^{\circ} \mathrm{C}$. The calculation was also performed for $3500 \mathrm{~J} / \mathrm{kg}^{\circ} \mathrm{C}$. It did not affect the calculated wheel temperature significantly but had a crucial effect on the calculated value of the brake shoe temperature.

Vernersson used the two-dimensional axisymmetric FE model to determine the average temperature on the surface of the brake shoe and wheel during braking $[50,51]$. The method is applicable to the temperature field calculations concerning stop brake applications, drag brake applications as well as multiple brake applications accounting for cooling of the friction pair. The partition of the frictional heat generated in the course of brake application between the wheel and the brake shoe is defined in a similiar way as in a paper by Petersson [37]—it depends on the thermal resistance of the friction elements:

$$
\begin{aligned}
& q_{\mathrm{w}}=\frac{T_{\mathrm{b}}^{\text {cont }}-T_{\mathrm{w}}^{\text {cont }}}{R_{\mathrm{w}}+R_{\mathrm{b}}}+\frac{R_{\mathrm{b}}}{R_{\mathrm{w}}+R_{\mathrm{b}}} q^{\text {brake }} \\
& q_{\mathrm{b}}=\frac{T_{\mathrm{w}}^{\text {cont }}-T_{\mathrm{b}}^{\text {cont }}}{R_{\mathrm{w}}+R_{\mathrm{b}}}+\frac{R_{\mathrm{w}}}{R_{\mathrm{w}}+R_{\mathrm{b}}} q^{\text {brake }}
\end{aligned}
$$

where

$q^{\text {brake }}=q_{\mathrm{w}}+q_{\mathrm{b}}$

and

$q^{\text {brake }}=\bar{q}^{\text {brake }}\left(1+\gamma\left(\xi_{t}-\frac{1}{2}\right)\right)$

$\bar{q}^{\text {brake }}=\frac{Q^{\text {brake }}}{B L_{\mathrm{b}}}$

$q$-heat flux, $T^{\text {cont }}$ - contact temperature, $R$-thermal resistance $\left(\mathrm{m}^{2}{ }^{\circ} \mathrm{C} / \mathrm{W}\right), \gamma$-axial heat distribution parameter, $\xi_{t}$-dimensionless axial coordinate across the wheel tread introduced to account for axial variation of heat flux ( $\xi_{t}=0$ at the field edge and $\xi_{t}=1$ at the flange side of the

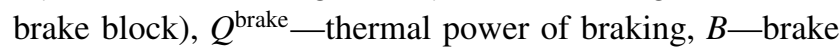
shoe width, $L_{\mathrm{b}}$-length per one brake shoe. Subscripts $\mathrm{b}$ and $\mathrm{w}$ denote brake shoe and wheel respectively.

Cooling of the friction elements by convection and radiation is accounted for. It is worth pointing out that heat transfer to the rail is introduced in the discussed model (rail chill). Two approaches are discussed in the study, namely (1) perfect thermal contact between the wheel and the rail (equal temperature at the contact interface) and (2) thermal resistance being the consequence of the film existing on the wheel-rail interface (temperature jump at the interface). For perfect thermal contact, the thermal power conducted from wheel to rail $Q_{\mathrm{r}}^{\text {perfect}}$, was given as follows:

$$
Q_{\mathrm{r}}^{\text {perfect }} \approx 6.99 \frac{b \lambda}{\sqrt{\kappa}}\left(T_{\mathrm{w} 0}-T_{\mathrm{r} 0}\right) \sqrt{\frac{a v}{8 \pi}}
$$

where $a, b$-semi-axes of wheel-rail contact ellipse, $\lambda-$ thermal conductivity, $\kappa$ - thermal diffusivity, $T_{\mathrm{w} 0}$-wheel temperature prior to contact with the rail, $T_{\mathrm{r} 0}$-rail temperature prior to contact with the wheel, $v$-sliding speed.

Moreover, an analysis was carried out which showed that thermal power related to the wheel-rail rolling contact and wheel slipping is almost negligible as compared to thermal power generated in the course of the stop brake application (initial velocity of $100 \mathrm{~km} / \mathrm{h}$, axle load of $22.5 \mathrm{t}$ and average deceleration of $0.385 \mathrm{~m} / \mathrm{s}^{2}$ generate maximum braking power of $152 \mathrm{~kW}$ while the power related to the rolling contact is only $2.2 \mathrm{~W}$ ).

An example of the numerical calculation showed that the rail chill may have significant influence on the temperature of the wheel tread during braking. The results of calculation indicated that, depending on operating 
conditions and material of the brake shoe, large part of the thermal power generated during braking (even more than $25 \%$ ) enters the rail.

In a paper published by Vernsersson in parallel to [50], the model is calibrated for three different brake block materials using experimental data (temperature measurement) [51].

The two-dimensional, axisymmetric model presented by Vernersson [50] was calibrated by Teimourimanesh et al. with the experimental data in [44] and used to calculate the temperature evolution in the course of metro route profile simulation [45]. The numerical analysis comprised 30 stop brake applications each followed by a short cooling period and a phase to cool down the friction pair to ambient temperature. In normal operation, braking performance on metro trains is mainly ensured by electrodynamic brake. The analysed case concerns however only friction braking, a worst-case scenario which must also be considered in the brake system design.

Temperature-dependent wheel material properties (ER7 steel) were introduced in the model. Flange deflection related to stop brake application was determined. In addition, a three-dimensional FE model was used to determine stress related to mechanical load resulting from wheel-rail contact. The numerical simulation accounted for three scenarios of mechanical load, namely the train: (1) travelling on a straight track, (2) negotiating a curve and (3) passing switch or crossing, which are characterised by different position of wheel-rail contact on the wheel profile. Residual stress induced in the wheel in the course of the manufacturing process was introduced in the model. The combined results from thermo-mechanical and mechanical analysis were used to calculate fatigue damage of the wheel.

Babu and Prasad [43] performed a coupled (structural and thermal) field analysis. The FE model was two-dimensional and non-axisymmetric. Structural analysis allowed to determine the circumferential contact pressure distribution. The simulation concerned a stop brake application from the initial velocity of $40 \mathrm{~km} / \mathrm{h}$ and was divided into 100 steps, each lasting 0.18 s. Calculations were carried out with the convective heat disspation to the ambient accounted for (a constant heat transfer coefficient at $90 \mathrm{~W} /$ $\mathrm{m}^{2}$ was assumed in the model) and with no convective cooling. The heat flow into to the wheel $\left(q_{\mathrm{W}}\right)$ and to the brake shoe $\left(q_{\mathrm{L}}\right)$ were defined as:

$$
\begin{aligned}
& q_{\mathrm{W}}=\gamma \mu p V \\
& q_{\mathrm{L}}=(1-\gamma) \mu p V
\end{aligned}
$$

The coefficient of friction $\mu$ was assumed to be constant and had a value of $0.175 . \gamma$ is heat partition ratio related to density $\rho$, specific heat $c$ and thermal conductivity $k$ (subscripts $\mathrm{W}$ and $\mathrm{L}$ refer to the wheel and brake shoe respectively):

$$
\gamma=\frac{q_{\mathrm{W}}}{q_{\mathrm{W}}+q_{\mathrm{L}}}=\frac{1}{\left(1+\rho_{\mathrm{L}} c_{\mathrm{L}} k_{\mathrm{L}} / \rho_{\mathrm{W}} c_{\mathrm{W}} k_{\mathrm{W}}\right)^{\frac{1}{2}}}
$$

In the presented example, $99 \%$ of the heat generated in the course of the brake application was transferred to the wheel and only $1 \%$ to the brake shoe. In order to reduce the computational effort, the wheel was considered rigid-the authors verified that it has no significant influence on the results of calculation.

The numerical analysis was preceded by a full-scale dynamometer test used to determine the braking time, velocity dependence on time as well as initial and final temperature on the surface of the wheel. The numerical calculation results were in very good agreement with the experimental measurements in terms of final temperature (measured value: $332 \mathrm{~K}$, calculated values: $335.77 \mathrm{~K}$ and $335.99 \mathrm{~K}$, with convective cooling considered and without it respectively). Also the velocity decrease in time reflected well its variation in the experimental test.

The authors investigated the influence of the rotational velocity on circumferential contact pressure distribution. Comparison of the results at $4 \mathrm{rad} / \mathrm{s}$ and $10 \mathrm{rad} / \mathrm{s}$ lead to the conclusion that the effect of the velocity on pressure distribution is negligible.

Milošević et al. [35] created a three-dimensional FE model of a tread-braked wheel with brake blocks in $2 \mathrm{xBgu}$ configuration (i.e. two brake shoes per each side of the wheel). The numerical calculation of temperature field evolution regarded drag brake application lasting $300 \mathrm{~s}$ at three velocities $(20 \mathrm{~km} / \mathrm{h}, 40 \mathrm{~km} / \mathrm{h}$ and $60 \mathrm{~km} / \mathrm{h})$ and two values of contact force $(20,379 \mathrm{~N}$ and $37,162 \mathrm{~N}$ per brake block), i.e. in total six cases were analysed.

Transient heat transfer equation used in the numerical calculations was given as:

$\rho C_{\mathrm{p}} \frac{\partial T}{\partial t}+\nabla(-k \nabla T)=-\rho C_{\mathrm{p}} u \nabla T$

where $\rho$-density, $C_{\mathrm{p}}$-specific heat capacity, $k$-thermal conductivity, $u$-velocity field.

The coefficient of friction was assumed to be constant at 0.115 regardless of the operating conditions of the analysed cases. Convective cooling and radiation was accounted for in the model. Perfect thermal contact on the wheel-shoe interface was assumed.

As expected for drag brake application, the maximum temperature increased as the velocity and contact pressure increased and was the highest at the end of simulation, i.e. at $t=300 \mathrm{~s}$. The highest temperature values were obtained on the wheel surface $(r=625 \mathrm{~mm})$, the lowest in the wheel hub area. For the brake application with the highest power (velocity of $60 \mathrm{~km} / \mathrm{h}$ and contact force of 37,162 N 
per brake block), the maximum calculated temperature on the wheel surface was $772.52{ }^{\circ} \mathrm{C}$.

It was found that the ratio of the calculated maximum temperature at higher and lower contact force $(37,162 \mathrm{~N}$ and 20,379 $\mathrm{N}$ per brake block respecitively) is approximately constant at $1.72-1.76$ depending on the velocity. The authors compared calculation results at $60 \mathrm{~km} / \mathrm{h}$ and 20,379 N per brake block (maximum calculated temperature was $437.22{ }^{\circ} \mathrm{C}$ ) with the results of calculation in similiar conditions, published in literature $\left(\sim 310^{\circ} \mathrm{C}\right.$ and $\sim 350{ }^{\circ} \mathrm{C}$ ) and concluded that this constitutes sufficient agreement and the presented method can be considered therefore as valid.

Esmaeili et al. [20] presented a comprehensive methodology to predict cracking and estimate the lifespan of railway wheel which is subject to thermomechanical load related to braking and rolling contact (this study is a further development of the work presented in [9]). In general, three braking cases were analysed in the study, namely stop brake applications from the initial velocity of $160 \mathrm{~km} / \mathrm{h}$ and $130 \mathrm{~km} / \mathrm{h}$ with sintered brake shoe and stop brake application from $160 \mathrm{~km} / \mathrm{h}$ with composite organic brake shoe. In each case normal force exerted on the brake shoe was $30,000 \mathrm{~N}$. The corresponding brake applications (40 repetitions) were conducted on the full-scale dynamometer in order to obtain the relevant experimental data (braking power, temperature evolution etc.).

Low cycle fatigue tests of ER7 steel were performed to acquire the data necessary to model the plastic behaviour of the wheel material. The tests were carried out at several temperatures between 20 and $625{ }^{\circ} \mathrm{C}$. The experimental measurement of temperature fields (by means of a thermal camera) led to observation of the localised high-temperature areas, i.e. a phenomenon called thermal banding related to thermoelastic instability described by Barber [4]. Thermal banding was detected for sintered brake shoes with two frequently occuring patterns, namely (1) two bands, each $25 \mathrm{~mm}$ wide and (2) a single hot band $(50 \mathrm{~mm}$ wide, observed in the course of the brake applications from the initial velocity of $160 \mathrm{~km} / \mathrm{h}$ and $40 \mathrm{~mm}$ when the initial velocity was $130 \mathrm{~km} / \mathrm{h}$ ). Nominal width of the contact area was $80 \mathrm{~mm}$. For brake applications with composite organic brake shoes, the temperature distrbution was approximately uniform.

During the dynamometer test, intermittent inspections were carried out to monitor the occurence and propagation of cracks. No cracking was detected when composite organic brake shoe was used. With sintered material, cracks appeared after 11th brake application (initial velocity of $160 \mathrm{~km} / \mathrm{h}$ ) and between 20th and 30th brake application (initial velocity of $130 \mathrm{~km} / \mathrm{h}$ ).

The FE simulations were carried out for each set of the operating conditions and three contact patterns, namely (1) two bands, (2) a single band and (3) contact on the entire width of the brake shoe. The non-uniform pressure distribution was accounted for by defining the contact only on the prescribed section along the width of the brake shoe. A combination of thermomechanical FE simulation and fatigue analysis allowed for estimation of the critical strain. This, in turn, led to estimation of the wheel lifespan (number of braking cycles at the prescribed operating conditions after which the critical strain in the wheel is exceeded). For the contact patterns which are characteristic of specified operating conditions (uniform contact for the composite organic brake shoe, a single band, $40 \mathrm{~mm}$ wide for sintered brake shoe and the initial velocity of $130 \mathrm{~km} / \mathrm{h}$ and a single band, $50 \mathrm{~mm}$ wide for sintered brake shoe and the initial velocity of $160 \mathrm{~km} / \mathrm{h})$ the estimated lifespan $(42$, 30 and 12 cycles respectively) and the experimental results were compared. The estimation agreed well with the crack occurence in the course of the dynamometer test-for sintered brake shoes the cracks appeared between 20th and 30 th braking cycle and after 11th cycle in respective cases. No cracks were detected after 40 braking cycles with composite organic material.

In Wasilewski and Grześ [54], the authors presented temperature evolution calculations for a tread-braked wheel subject to stop brake application. A three-dimensional model of a tread brake in $1 \mathrm{xBg}$ configuration was created. In order to reduce the computational effort, a simplified geometry of the wheel hub was assumed. Furthermore, the FE mesh was coarse in the areas where no significant change in temperature was expected (e.g. wheel hub and wheel web) and very fine in the vicinity of the contact interface. Perfect thermal wheel-brake shoe contact was assumed in the model. The analysed case concerned brake application from $80 \mathrm{mph}(128.7 \mathrm{~km} / \mathrm{h})$ with normal force exerted on the brake block of 28,590 N.

The main aim of this study was to compare the results of temperature field calculation considering two different assumptions: (1) constant value of the coefficient of friction in the course of the brake application (2) coefficient of friction dependent on operating conditions. In the latter case, the data concerning evolution of the coefficient of friction, wheel velocity and normal force were acquired in the course of the full-scale dynamometer test. In the first case, constant, mean value of the normal force was introduced in the model. The value of the coefficient of friction was also constant and calculated from the experimental data as defined in [48]:

$$
\begin{aligned}
& \mu_{\mathrm{m}}=\frac{1}{S_{2}} \int_{0}^{S_{2}} \mu_{\mathrm{a}} \mathrm{d} S \\
& \mu_{\mathrm{a}}=\frac{F_{\mathrm{t}}}{F_{\mathrm{b}}}
\end{aligned}
$$


where $\mu_{\mathrm{m}}$-mean coefficient of friction, $S_{2}$-stopping distance from the point in time when normal force reaches $95 \%$ of the target value, $\mu_{\mathrm{a}}$-instantaneous coefficient of friction, $F_{\mathrm{t}}$-instantaneous braking (tangential) force, $F_{\mathrm{b}}$ instantaneous contact (normal) force.

The velocity decreased linearly from the initial value to zero at specified point in time (total braking time from the experimental results). In order to reflect the conditions from the dynamometer test, initial temperature distribution was introduced in the wheel (by a procedure named "preheating").

It was found that when the model accounted for variation of the coefficient of friction in the course of brake application, the average maximum calculated temperature $\left(272{ }^{\circ} \mathrm{C}\right)$ was closer to the experimental value $\left(282^{\circ} \mathrm{C}\right)$ as compared to the calculations based on the assumption that the coefficient of friction is constant $\left(336.6{ }^{\circ} \mathrm{C}\right)$. It was also observed that the temperature evolution is in better agreement with the experimental data when variation in the coefficient of friction is considered.

Wasilewski and Bułhak [53] carried out numerical calculations of temperature evolution in the course of drag brake applications. A three-dimensional FE model of tread brake in $1 \mathrm{xBg}$ configuration was employed. Considering the duration of the brake application (2700 s), simplifications were made to the wheel and brake shoe geometry, to reduce the computational effort. In particular, flange was not modelled - the wheel rim was represented by a hollow cylinder. Two cases were analysed which differed in the initial temperature of the friction pair $\left(17.5^{\circ} \mathrm{C}\right.$ and $\left.61.9^{\circ} \mathrm{C}\right)$ and the evolution of the coefficient of friction. In both cases constant velocity of $32 \mathrm{~km} / \mathrm{h}$ was maintained and the normal force exerted on the brake shoe was $6450 \mathrm{~N}$. The evolution of the coefficient of friction introduced in the model was determined by means of a full-scale dynamometer test and reflected its temperaturedependence.

The difference between experimental results and calculated average temperature (determined from values in three points corresponding to measurement points in the dynamometer test) at the end of brake applications was about $8 \%$. In addition, the authors concluded that accounting for dependency of the coefficient of friction on temperature allows for a good representation of temperature evolution in the course of drag brake application.

Abbasi et al. [1] investigated thermoelastic instability (TEI) phenomenon observed in railway tread brakes. The experimental part of the study was carried out using pinon-disc tribometer. The pin was made from P10 cast irona material widely applied in railway tread brakes, the disc was cut out of the rim of a railway wheel (ER8T steel). In the course of the test, mass wear of the pin was measured.
In addition, vertical displacement of the pin and disc support was measured. The disc temperature was controlled during the test-the heating unit was installed in the setup. Temperature was measured using three methods: (1) pyrometer was used to measure the temperature of the cylindrical part of the disc, (2) a thermal camera was used to determine temperature field on the side of the pin, pin holder and the disc, (3) infrared (IR) mirror was used to measure the temperature on top of the disc.

An axisymmetric, two-dimensional FE model of the experimental setup was employed to investigate the heat partition between the pin and the disc. It was assumed that the "third-body" exists between the pin and the disc and the heat is partitioned between the friction elements as presented in [50]. The model was calibrated with the experimental data.

TEI was investigated by using four "submodels" calculating contact pressure and temperature distribution, wear of the pin and related change in geometry and accounting for temperature-dependent material properties. To observe the variation in contact pressure and temperature distribution, the contact surface was divided into rectangular sections. It was found that with disc temperature increasing up to $500{ }^{\circ} \mathrm{C}$, the heat flux to the pin also increases. Above that temperature the ratio of the heat absorbed by the pin to the total heat flux decreases. Corresponding tendency was observed for specific wear of the cast iron pin. Analysis of the results of numerical calculations showed that local maxima of contact pressure and temperature appear and change position over time. It was concluded that the presented model may be applied to predict occurence of TEI for friction materials used in railway braking.

Vernersson used a two-dimensional FE model of a section of a tread braked railway wheel to study roughness induced by braking [49]. Two friction materials were considered, namely cast iron and organic composite for which, for the purpose of the analysis, two values of elastic modulus were considered. It was assumed that the coefficient of friction is constant in the course of simulation. Constant heat partition coefficients were defined in the model $(50 \%$ of the heat entered the wheel braked with cast iron shoe and $90 \%$ in the case of composite brake shoe). Wear of the friction material was accounted for in the model. Non-uniform heat flow distribution was imposed at the beginning of the simulation. Random and sinusoidal perturbation were analysed for cast iron brake shoe and only random perturbation for organic composite material. In the case of cast iron brake shoes, the result of the simulation indicated that in few seconds a two-band contact pattern is established at the brake shoe-wheel interface. For composite material the result depended on its elastic modulus. For the elastic modulus value below $1 \mathrm{GPa}$, the 
non-uniformities imposed initially have the tendency to reduce. For higher values of elastic modulus (above $2 \mathrm{GPa}$ ) the non-uniformities increase. When the sliding velocity was reduced from 100 to $50 \mathrm{~km} / \mathrm{h}$, the non-uniformities developed in a slower manner. In the simulation, more heat was transferred to the wheel with composite friction material and it lead to faster growth of non-uniformities in contact surface.

Variation in contact pressure and surface temperature along the wheel circumference was compared for composite materials with elastic modulus of $3 \mathrm{GPa}$ and $5 \mathrm{GPa}$. The material with lower elastic modulus generated lower variation in contact pressure and in consequence in surface temperature.

It was concluded by the author that the possible method to reduce wheel roughness is to use friction material characterised by low value of elastic modulus.

Caprioli and Ekberg [8] employed FEM to calculate stress and strain in the wheel subject to thermomechanical and mechanical load. The first was related to braking, the latter to rolling. The calculations were performed in partial slip and full slip conditions. Temperature-dependent wheel material properties were introduced in the model. The authors investigated the effect of modelling strategies on the accuracy of the results and computational effort.

It is worth noting that numerical FE models are also applied to analyse the heating and thermomechanical stress in railway wheels resulting from the rolling contact $[13,27]$.

\section{Temperature Calculations in Railway Disc Brake}

With the operating speed of passenger railway vehicles and the amount of energy dissipated during braking increasing and finally as the requirements concerning braking performance become more demanding, tread brake was superseded in contemporary vehicles by disc brake [36, 39, 47].

The most important advantage of disc brake over tread brake is that it allows to perform high-power brake applications without inducing thermal stresses in wheels [36]. It has a beneficial effect on safety of operation and servicelife of wheelsets. In addition, tread braked vehicles have tendency to generate rolling noise due to the tread-braked wheel-rail interface [47]. When compared to tread-braked vehicles, in particular those equipped with cast iron brake shoes, high value of the coefficient of friction between brake disc and composite brake pad, allows for using smaller (and lighter) brake cylinders. It is also reported, that disc brake, due to the frictional characteristics of composite brake pads, ensures approximately constant deceleration in the course of brake application [36].

In a typical disc-braked railway vehicle, brake disc may be axle-mounted or wheel-mounted, which depends on the space available in the bogie [47]. In general, power bogies are characterised by less space available as compared to trailer bogies, hence wheel-mounted brake discs are quite often installed on locomotives and power bogies of multiple units, whereas axle-mounted brake discs are installed on passenger coaches and trailer bogies of multiple units.

Brake discs are often designed with channels improving air-cooling efficiency (cooling fins) but solid, non-ventilated brake disc also find application [18]. The decision on particular brake disc design depends on operating conditions-if the brake applications are less frequent and of higher power (e.g. high-speed trains), higher thermal capacity is desirable. By contrast, when the brake applications are quite frequent and at lower initial velocity (e.g. metro trains), then cooling efficiency plays a crucial role [36].

In this section of the paper, the studies concerning application of FEM to determine temperature fields in a railway disc brake are discussed.

Ghadimi et al. [21] used a three-dimensional FEM model of the wheel-mounted brake disc of a locomotive to determine temperature evolution on the surface of the disc and the cooling fins in the course of a single emergency brake application. Computational fluid dynamics software was used to calculate heat transfer coefficient, related to cooling by air, at each step of the simulation. Therefore, efficiency of the cooling varied in the course of the analysed brake application. The pad and brake disc were considered as semi-infinite solids and the heat partition (generation) $\lambda$ ratio was defined as:

$\lambda=\frac{q_{\mathrm{d}}^{\prime \prime}}{q_{\mathrm{p}}^{\prime \prime}}=\left(\frac{\rho_{\mathrm{d}} C_{\mathrm{d}} k_{\mathrm{d}}}{\rho_{\mathrm{p}} C_{\mathrm{p}} k_{\mathrm{p}}}\right)^{\frac{1}{2}}$

where $q^{\prime \prime}$-absorbed heat flux, $\rho$-density, $C$-specific heat capacity, $k$-thermal conductivity and subscripts $\mathrm{d}$ and $\mathrm{p}$ refer to disc and pad respectively.

Value of the coefficient of friction was assumed to be constant in the entire course of the analysed brake application. The calculated temperature evolution on the disc and fins surface was compared with the experimental results. Maximum calculated temperature value on the disc surface was approximately $240{ }^{\circ} \mathrm{C}$ whereas maximum measured temperature was about $270{ }^{\circ} \mathrm{C}$. In addition, temperature evolution during brake applications from the initial velocity of $160 \mathrm{~km} / \mathrm{h}$ at five different deceleration rates (between 0.8 and $1.2 \mathrm{~m} / \mathrm{s}^{2}$ ) was calculated-the maximum temperature at the lowest deceleration rate was 
$197.53{ }^{\circ} \mathrm{C}$, for the highest deceleration it was $28.42{ }^{\circ} \mathrm{C}$ higher.

Ghadimi et al. [22] is a continuation of the work published in [21]. Using the same model, numerical calculation of temperature fields in the course of drag and stop brake application were carried out. The results were used as input data for calculation of thermal Huber-von Mises stress and deformation of the brake disc. Thermal stress $\sigma$ was defined as:

$\sigma=E \alpha\left(T-T_{0}\right)=E \alpha(\Delta T)$

where $E$-modulus of elasticty, $\alpha$ - thermal expansion coefficient, $T$-temperature, $T_{0}$-reference temperature.

While the temperature during drag brake application was significantly higher than after stop brake application, thermal stress however was lower. This finding led to the conclusion, that the design of the cooling fins is correct.

Dufrénoy and Weichert determined temperature evolution on the surface of the railway brake disc comparing calculations at two different assumptions, namely that: (1) pressure distribution on the brake pad is uniform and (2) disc-pad contact area changes in the course of the brake application as a consequence of wear and deformation of friction elements [17]. Another assumption was that at the rotational velocity considered in the study, circumferential temperature gradient may be neglected, therefore it was justified to apply a two-dimensional model. Heat dissipation by convection and radiation was taken into account. Maximum calculated temperature on the disc surface was siginifcantly higher in the case where non-uniform pressure distribution was accounted for $\left(694.8^{\circ} \mathrm{C}\right.$ as compared to $329.5{ }^{\circ} \mathrm{C}$ with uniform pressure distribution assumption). Furthermore, high radial temperature gradient was observed in this case. This result was confirmed by thermographic temperature distribution measurement during full-scale dynamometer test and is in line with the findings of Barber [4, 5].

Sensitivity study of the model indicated that Young's modulus and the coefficient of thermal expansion of the pad material have an important effect on the maximum temperature and the influence of thermal conductivity of the pad material is negligible. The higher the value of Young's modulus, the shorter time it takes for the temperature to reach its maximum. Calculations carried out at low value of Young's modulus resulted in the temperature evolution similiar to the case where uniform pressure distribution was assumed.

Benseddiq et al. used two-dimensional FE model to calculate the temperature gradients while optimising shape of the railway brake pad [7]. The goal was to find the geometry for which the most uniform pressure distribution on pad-disc contact surface will be established. The same thermomechanical algorithm as in [17] was applied.
According to the authors, high radial thermal gradient is a consequence of non-uniform pressure distribution. Hence, the basic assumption for the analysis was that the optimal pad geometry will be characterised by a minimal radial thermal gradient. The analysis included investigation of the maximum temperature dependency on the number of grooves in the pad, mechanical properties of the friction material and intermediate layer as well as backplate thickness. Compressibility of the pad was modified by changing modulus of elasticity from 250 to $3150 \mathrm{MPa}$. The observed tendency was that the lower the modulus of elasticity, the lower the value of calculated maximum temperature. It was concluded that the more elastic the friction material is, the pressure distribution is more uniform. Change in Young's modulus of the intermediate layer had similar influence on the maximum temperaturethe stiffer the substrate, the higher the value of maximum temperature during brake application. Another possible modification that was analysed in this study concerned number of grooves in the brake pad. When grooves are introduced in the pad, the disc-pad contact becomes more elastic. It was found that in the case where four horizontal grooves were introduced, the maximum calculated temperature decreased from 1136 to $600{ }^{\circ} \mathrm{C}$ as compared to the design with one groove. It was also observed that when both modulus of elasticity of the friction material and number of grooves are modified, the more elastic the material is, the influence of grooves number is more pronounced. Furthermore, the higher number of grooves is introduced in the pad, the effect of change in the elasticity of the friction material decreases. To further improve the uniformity of pressure distribution, a steel reinforcement, $10 \mathrm{~mm}$ thick, was introduced in the model. The calculations confirmed that as flexibility of the pad as a whole was limited by the reinforcement, further reduction of the calculated maximum temperature was observed. An experimental study on a full-scale dynamometer was performed to verify the numerical analysis. Two sets of brake pads were tested-first with one groove and the other with three grooves. In both cases friction material with equal modulus of elasticity was used. 12 thermocouples were installed in the brake pads, 3 to $4 \mathrm{~mm}$ under the friction interface. The test confirmed that increasing the number of grooves in the pad led to more uniform temperature distribution. Finally, the authors presented a proposed new design of the brake pad with increased number of grooves, different shape of the friction surface and with a steel reinforcement. It was concluded that a separate study is neceessary to account for effects concerning circumferential temperature distribution.

Optimisation was also the subject of a paper by Missori and Sili [36]. Two-dimensional FE model of the brake disc section was used to determine temperature evolution in the 
course of drag and single stop brake application. The operating conditions reflected constant-velocity downhill braking at $70 \mathrm{~km} / \mathrm{h}$ and stop brake application from approx. $240 \mathrm{~km} / \mathrm{h}$ with two stages of deceleration rate (contact force). The effect of the brake disc design, namely the number of cooling fins $(0,36$ and 72$)$, friction ring thickness $(12 \mathrm{~mm}, 20 \mathrm{~mm}$ and $28 \mathrm{~mm})$ and cooling fins width (54 mm, $70 \mathrm{~mm}$ and $86 \mathrm{~mm}$ ), on temperature distribution and evolution was analysed.

Additional calculations were performed concerning a full, non-ventilated brake disc, having equal internal and external radius of the friction ring as well as equal mass and thermal capacity as compared to the reference brake disc (thickness of approx. $70 \mathrm{~mm}$ ). It was assumed that the entire heat generated in the course of brake application is absorbed by the disc, the heat flux distribution on the disc surface is uniform, and the circumferential and radial temperature gradient are negligible (only the axial temperature gradient was considered).

Temperature-dependent changes in the thermophysical properties of the brake disc material (cast iron) and air were taken into account. Heat exchange was calculated in a different way for the surface in contact with brake pads and the cooling fins side. Coefficient of heat transfer in the first case was assumed to be a sum of convective term and radiation term, whereas in the latter case the radiation term was neglected. Cooling efficiency of the disc was investigated by experimental tests.

It was concluded that a slight increase in thickness (and consequently its thermal capacity) of the brake disc (e.g. $5 \mathrm{~mm}$ ) might be an effective way to substantially reduce the maximum temperature in the course of both drag and stop brake applications, which in turn has a beneficial effect on the service life of brake pads. Doubling the number of cooling fins (from 36 to 72) resulted in improvement in brake disc cooling efficiency-the difference in calculated surface temperature, immediately after brake release, was $40{ }^{\circ} \mathrm{C}$, while 20 minutes later it increased to approx. $90{ }^{\circ} \mathrm{C}$. The design without cooling fins, i.e. a non-ventilated brake disc, had a poor cooling efficiency which caused higher maximum temperature prior to brake release and substantially longer cooling time (maximum calculated temperature for non-ventilated brake disc was approx. $510{ }^{\circ} \mathrm{C}$ and for brake disc with 72 cooling fins it was approx. $430{ }^{\circ} \mathrm{C}$, whereas temperature at the end of calculation, i.e. 20 minutes after brake release, was approx. $340{ }^{\circ} \mathrm{C}$ as compared to approx. $80^{\circ} \mathrm{C}$ for brake disc with 72 cooling fins). On the other hand, in the course of stop brake application, non-ventilated brake disc was characterised by the lowest calculated maximum temperature (approx. $340{ }^{\circ} \mathrm{C}$ as compared to $360{ }^{\circ} \mathrm{C}$ and $370{ }^{\circ} \mathrm{C}$ for brake disc with 72 cooling fins and 36 cooling fins respectively).
The authors concluded that such brake disc design may not be suitable for railway applications, since it operates well mainly when subject to high-power stop brake applications.

However, axle-mounted, non-ventilated brake discs are used for example on trailer bogies of French high-speed trains (Train à Grande Vitesse-TGV) [18]. Dufrénoy and Weichert used three-dimensional FEM model to investigate the mechanism of crack formation on the brake discs of TGV trains. Analysis of the TGV brake discs indicated that two main types of cracks can be distinguished: (1) a relatively dense network of microcracks and (2) macrocracks, which propagate mostly in the radial direction. The thermal gradients observed in the course of experimental tests of a TGV brake disc on a full-scale dynamometer were classified into five types, taking into account their size, thermal level and duration: (1) regional thermal gradient related to almost uniform pressure distribution, (2) macroscopic hot spots, which appear in their "stable" form longer than $10 \mathrm{~s}$, (3) hot bands caused in general by nonuniform pressure distribution in pad-disc contact, (4) gradients on hot bands and (5) very short flashes of high temperature on contact asperities. The authors focused on the case where macroscopic hot spots are present. Since the distribution of the hot spots is regular (in the analysed case, a total of twelve hot spots, six per friction ring), the authors used a three-dimensional model of the disc section, namely one-sixth of the circumference of one friction ring. The mechanical loading related to friction was not accounted for, as from the macroscopic perspective it is significantly lower than thermomechanical loading. However, it was noted that when highly non-uniform pressure distribution occur, the mechanical component may significantly contribute to the overall loading.

The temperature distribution in the course of stop brake application was calculated (initial velocity of $300 \mathrm{~km} / \mathrm{h}$, energy of $13.9 \mathrm{MJ}$ dispersed in $213 \mathrm{~s}$ ), imposing the defined non-uniform heat flux distribution. The results of calculation were compared with experimental termographs. The calculated maximum temperature $\left(910{ }^{\circ} \mathrm{C}\right)$ and the value measured in the experiment $\left(952^{\circ} \mathrm{C}\right)$ were reached at the same point in time (72 s). Similiar to calculation, six macroscopic hot spots were observed in the experiment, albeit differing in shape-those in the experiment were more localised.

As thermal and mechanical analysis were uncoupled, the temperature field at the point in time when the maximum temperature was reached, constituted the input data for the calculation of angular stress and plastic strain. The results were verified with the measurement of residual stress on the brake disc of the TGV train. The experimental results were of the same order as calculated values and confirmed that lower stress occur in the radial direction as compared 
to circumferential direction. The experiment supported also the findings from the numerical calculation that the highest stress values are present in the vicinity of the hot spot.

Finally, a cyclic loading analysis (seven consecutive brake applications) was carried out to study stress-strain hysteresis loops-a stabilisation of the loops was achieved after sixth consecutive stop brake application.

Based on the experimental and numerical findings, the authors concluded that cracking mechanism of railway brake disc may be explained by its being subject to the cyclic thermoplastic loading.

Also TGV brake disc, albeit wheel-mounted type installed on motor bogies, was analysed in an article by Tirovic [47]. The author employed FEM calculations in the design process. Using the three-dimensional model of a brake disc section, new design concept was tested by temperature fields calculation in the course of emergency stop brake application. The initial velocity was $320 \mathrm{~km} / \mathrm{h}$ with two deleceration rates defined, namely $1.0 \mathrm{~m} / \mathrm{s}^{2}$ between 320 and $215 \mathrm{~km} / \mathrm{h}$ and $1.3 \mathrm{~m} / \mathrm{s}^{2}$ between 215 and $0 \mathrm{~km} / \mathrm{h}$. Initially, the author focused on modelling bulk thermal effects (as defined in [14]), the macroscopic effects, such as hot spots were considered at the later stage of the design process. Temperature-dependent material properties were accounted for, however to reduce calculation time, in the initial phase of the process, plasticity was not modelled. In addition to temperature fields, Hubervon Mises stresses and disc deformation were determined. The brake disc manufactured according to the design proposed in the paper was tested extensively on a full-scale dynamometer, passed the approval procedure, including inservice testing and was successfully introduced in the operation of TGV trains. To summarise, in Tirovic's work, FEM has proven to be a very effective tool to aid in the design process of railway brake disc.

A paper by Kim et al. concerns thermal stress analysis of a railway brake disc under non-uniform contact pressure distribution [31]. A three-dimensional FE model was used to calculate temperature distribution in the course of a single stop brake application from an initial velocity of $150 \mathrm{~km} / \mathrm{h}$ and initial temperature of the friction pair of 100 ${ }^{\circ} \mathrm{C}$. In the first step, pressure distribution was determined, considering the geometry of the friction pair and rotation of the disc. The resulting non-uniform pressure distribution was imposed during temperature field calculation. For the purpose of comparison, a case with uniform pressure distribution assumption was analysed.

The Huber-von Mises stresses in the brake disc were determined for temperature distribution at a point in time when the maximum temperature on the disc surface was reached $\left(159{ }^{\circ} \mathrm{C}\right.$ under non-uniform pressure distribution and $151{ }^{\circ} \mathrm{C}$ under uniform pressure distribution). The calculated maximum Huber-von Mises stress was slightly lower under non-uniform pressure distribution assumption (100 MPa as compared to $103 \mathrm{MPa}$ when pressure distribution was considered uniform) and its location agreed with that of the cracks on the brake disc in service, unlike in the other analysed case. The authors concluded that in case of thermal stress analysis, the assumption of nonuniform pressure distribution ensures more reliable calculation results.

The purpose of the work by $\mathrm{Li}$ et al. [34] was to investigate the mechanism of crack formation on the brake discs in service on China Railway High-speed (CRH) rolling stock. The influence of operating conditions on crack propagation was studied by analysing three cases: (1) emergency brake applications from the initial velocity of $300 \mathrm{~km} / \mathrm{h}$, (2) emergency brake applications from the initial velocity of $200 \mathrm{~km} / \mathrm{h}$ and (3) service brake applications from the initial velocity of $200 \mathrm{~km} / \mathrm{h}$, where regenerative braking played a significant role in the total braking performance. For the analysis of the first case scenario, a brake disc, which was subject to emergency brake applications from the initial velocity of $300 \mathrm{~km} / \mathrm{h}$, was dismantled from the motor axle. The length of the cracks exceeded the limit permitted by maintenance rules, therefore the disc was withdrawn from service. The second scenario was investigated by full-scale dynamometer testing-almost 1000 emergency brake applications were performed. The third case was studied by monitoring the brake discs operating in normal service for 6 months, which resulted in approximately 8000 service brake applications. No emergency brake applications were performed during this period. The authors analysed overheated areas and fatigue cracks evolution by comparing the photographs. The distinction has been made between crackles, i.e. network of superficial material discontinuities and cracks, i.e. deep and long fractures.

Five samples were cut out from brake discs that were subject to emergency brake applications from the initial velocity of $300 \mathrm{~km} / \mathrm{h}$. The specimens were fractured along the cracks and their geometry was analysed. The cracks were half-elliptic in shape and their maximum depth was between 4.0 and $5.4 \mathrm{~mm}$. It was found that the fatigue cracks propagated mainly in radial direction. Hardness was measured at several points along the thickness of the disc. Furthermore, the microstructure of the material was examined which indicated a phase change in the disc material in the overheated areas. Finally, elemental analysis of the areas in the close vicinity of the cracks indicated substantial oxidation concerning brake disc subject to emergency brake applications from the initial velocity of $300 \mathrm{~km} / \mathrm{h}$, while the areas close to the fatigue cracks on the brake disc subject only to service brake applications from the initial velocity of $200 \mathrm{~km} / \mathrm{h}$ were not oxidised. It was 
concluded that increase in braked energy leads to conditions more favourable in terms of crack propagation.

Numerical simulations were performed for the three case scenarios mentioned before. Transient FE analysis was used to calculate temperature fields in the course of brake applications and subsequent cooling. Perfect paddisc contact was assumed in the simulation, wear of the friction elements was not accounted for. Circumferential stress was calculated on the surface on the disc as well as $5 \mathrm{~mm}, 10 \mathrm{~mm}$ and $18 \mathrm{~mm}$ below.

The residual tensile stress after cooling was present only in simulations concerning emergency brake applications. The residual tensile stress after emergency brake application from the initial velocity of $200 \mathrm{~km} / \mathrm{h}$ was almost negligble at the depth of $5 \mathrm{~mm}, 10 \mathrm{~mm}$ and $18 \mathrm{~mm}$ below the disc surface, and was approximately $50 \mathrm{MPa}$ on the disc surface. It was concluded that this corresponds to crackle formation as observed on the disc during full scale dynamometer test.

In the case of emergency braking from the initial velocity of $300 \mathrm{~km} / \mathrm{h}$, the circumferential stress on the disc surface was compressive in the initial stage and changed to tensile stress during cooling period. Subsequent brake applications and cooling periods resulted in similiar circumferential stress evolution. It was concluded that cyclic change between compressive and tensile circumferential stress close to the disc surface is a contributing factor to crack propagation. The depth at which calculated residual tensile stress was present agreed well with the crack depth observed on specimens cut out from brake disc from CRH rolling stock.

The simulation concerning brake disc subject to service brake applications from the initial velocity of $200 \mathrm{~km} / \mathrm{h}$ showed practically no residual circumferential stress after cooling period which led to the conclusion that under these operating conditions fatigue cracks do not propagate. It was supported by the analysis of the brake discs in normal operation on CRH rolling stock.

The authors suggested that in order to avoid fatigue cracks formation and propagation, it is crucial to eliminate residual circumferential stress. The proposed method consists in brake application at low contact pressure to gradually and uniformly increase the disc temperature.

$\mathrm{Wu}$ et al. proposed a method to estimate the lifespan of a railway brake disc related to crack propagation resulting from cyclic thermomechanical loads [55]. The authors determined the temperature fields in the course of emergency brake application from the initial velocity of $400 \mathrm{~km} / \mathrm{h}$. Cooling of the friction pair was accounted for by defining convection exchange coefficient (air-cooling) and radiation exchange coefficient. The calculation results showed localised high temperature areas, i.e. hot spots. The calculated maximum temperature in a single stop brake application (approx. $681{ }^{\circ} \mathrm{C}$ ) was in very good agreement with experimental measurement (approx. $686^{\circ} \mathrm{C}$ ). A single semi-eliptical thermal fatigue crack, $2 \mathrm{~mm}$ long, was introduced in one of the hot spots. Its development in relation to number of emergency brake applications was investigated by means of advanced modeling techniques (extended finite element method-XFEM and virtual-node polygonal finite element method-VPM). It took more than 277,000 emergency brake applications for the crack to reach length of $100 \mathrm{~mm}$ which was regarded as the maximum permissible value.

The authors estimated that when a thermal fatigue crack of $2 \mathrm{~mm}$ is detected, the remaining service life of a brake disc is slightly more than 5 years.

In Grześ et al. [26], the authors presented results of temperature field calculations in the disc brake of a railway vehicle. A three-dimensional FE model of the brake pads and the disc was created. As the system is symmetrical along the central plane, only one half of the brake disc thickness and one set of brake pads were modelled. In order to reduce the computational effort, the cooling fins of the brake disc were not modelled, but the total mass of the disc was maintained by defining the appropriate thickness of the friction ring. Thermal diffusivity of the pad material was determined employing pulsed IR thermography. With known density and specific heat capacity, thermal conductivity was calculated. These thermophysical properties of the friction material were introduced in the FE analysis. The calculations concerned 10 stop brake applications with 4 different initial velocities $(110 \mathrm{~km} / \mathrm{h}, 95 \mathrm{~km} / \mathrm{h}, 65 \mathrm{~km} / \mathrm{h}$ and $35 \mathrm{~km} / \mathrm{h}$ ). The coefficient of friction was measured on the full-scale dynamometer-its mean value was introduced in the model and was assumed to be constant in the course of brake application. The results of temperature field calculations lead to the conclusion that during single stop brake application the disc is not heated uniformly-temperature gradients were observed in axial direction in the course of the entire braking. Furthermore, as the geometry of the pad-disc contact area was complex due to the grooves in the pad, the temperature distribution was found to be non-uniform.

In Yevtushenko et al. [60], the authors extended the work presented in [26]. A single and repeated brake applications of the diesel multiple unit (DMU) equipped with disc brake were subject of this study. Comparative analysis was carried out considering: (1) numerical solution of spatial mathematical model with application of FEM, (2) analytical solution of one-dimensional thermal problem of friction presented in [10], (3) experimental results published in [23]. To determine the temperature of the friction elements in the course of the $n$th brake application, following algorithm was employed: 
1. during first brake application $(n=1)$ the temperature of the friction elements is found from the numerical solutions of the boundary-value heat conduction problem;

2. once the brake disc stops, numerical problem of transient heat conduction considering cooling by convection is solved;

3. the average bulk temperature of the friction elements after one braking cycle is determined before the subsequent brake application commences and is introduced in the boundary condition as initial temperature;

4. after repeting steps 1 to 3 for $n$ times, the temperature fields are determined.

Results of numerical calculations concerning temperature evolution in the course of the 5th brake appllication in a series were compared with the analytical solution presented in [10] and with the experimental results published in [23]. The temperature values determined by both methods subject to comparison are in good agreement, although better correlation with the experimental data was achieved for results obtained with the FE model. The advantage of the presented numerical model is that it allows introduction of given geometry of friction elements. The limitation however is that it is necessary to perform simulation for brake pad and brake disc separately.

Two other papers are worth noting-despite the fact that they do not directly refer to railway braking, the presented results may find application in this field.

Qi and Day [40] investigated the effect of the actual contact surface on the temperature field in the disc brake. The temperature was calculated at 3 points on the contact surface. The authors concluded that the increase in the actual contact surface is related to decrease in local temperature values, while it does not affect the average temperature of the disc.

Alnaqi et al. [2] proposed a method to determine the parameters of the reduced-scale dynamometer test, so as to maintain operating conditions from the full-scale test and simulate the process of frictional heating as in the natural scale. The axisymmetric, two-dimensional FE model was verified with the experimental data and subsequently used to confirm the feasibility of the reduction method in operating conditions beyond those tested in the experiment.

\section{Summary and Conclusions}

In the design process of the railway vehicle braking system it is of utmost importance to determine the operating temperature of the friction pair. The thermal load, which friction elements will be subject to, depends on both the design of the vehicle and its braking system but also on the operating conditions in service. It is therefore justified to model frictional heating of the friction elements in the design phase, instead of performing costly and time-consuming bench tests.

The articles discussed in this review are characterised by diverse aims, i.e. optimisation of the brake disc geometry, optimisation of the brake pad shape, determination of mechanical and thermal stresses, investigation of crack formation and thermoelastic instability phenomenon. It shows how crucial a role numerical simulations play in the process of design and evaluation of braking systems for railway vehicles. The analysis of the published literature indicates that the researchers who model frictional heating in railway brakes, very often assume the simplifiaction that the coefficient of friction is constant in the course of brake application. In reality, however, it strongly depends on operation conditions, such as sliding velocity and temperature $[12,24,29,41,42]$. An exception to this finding are studies by Wasilewski and Grześ [54] and Wasilewski and Bułhak [53] —in these studies the authors introduced in the model evolution of the coefficient of friction measured during full-scale dynamometer test. There are articles which discuss frictional heating, where authors assume linear dependency of the coefficient of friction on temperature [52, 46]. In Yevtushenko et al. [56, 59], the authors calculated temperature field with temperature-dependent coefficient of friction, employing the relations given by Chichinadze et al. [11]. Yevtushenko and Grześ introduced in [57] mutual coupling of temperature of the friction elements, their thermophysical properties, the coefficient of friction and finally rotational velocity of the brake disc. The subject of the study was, however, disc brake of a passenger car. Further development of this work was presented by Grześ [25]. No study is known to the author, which concerns numerical model of railway brake accounting for mutual coupling of temperature, thermophysical and tribological properties of the friction elements. Considering the specifics of railway braking, namely diversity of friction materials in service, brake types and configurations as well as wide range of operating conditions, which in turn have significant influence on the braking process, it is a worthwhile task to further develop the existing models.

Acknowledgements This article was supported by the National Science Centre of Poland (research project no. 2017/27/B/ST8/01249).

\section{Compliance with Ethical Standards}

Conflicts of interest The author states that there is no conflict of interest.

Open Access This article is distributed under the terms of the Creative Commons Attribution 4.0 International License (http:// 
creativecommons.org/licenses/by/4.0/), which permits unrestricted use, distribution, and reproduction in any medium, provided you give appropriate credit to the original author(s) and the source, provide a link to the Creative Commons license, and indicate if changes were made.

\section{References}

1. Abbasi S, Teimourimanesh S, Vernersson T, Sellgren U, Olofsson U, Lundén R (2014) Temperature and thermoelastic instability at tread braking using cast iron friction material. Wear 314(1):171-180

2. Alnaqi AA, Barton DC, Brooks PC (2015) Reduced scale thermal characterization of automotive disc brake. Appl Therm Eng 75:658-668

3. Association of American Railroads (1983) Procedure for the analytic evaluation of locomotive and freight car wheel designs. S-660-83. Association of American Railroads

4. Barber J (1967) The influence of thermal expansion on the friction and wear process. Wear 10(2):155-159

5. Barber J (1969) Thermoelastic instabilities in the sliding of comforming solids. Proc R Soc Lond A 312:381-394

6. Belhocine A (2017) FE prediction of thermal performance and stresses in an automotive disc brake system. Int $\mathbf{J}$ Adv Manuf Technol 89(9-12):3563-3578

7. Benseddiq N, Weichert D, Seidermann J, Minet M (1996) Optimization of design of railway disc brake pads. Proc Inst Mech Eng F J Rail Rapid Transit 210(1):51-61

8. Caprioli S, Ekberg A (2014) Numerical evaluation of the material response of a railway wheel under thermomechanical braking conditions. Wear 314(1):181-188

9. Caprioli S, Vernersson T, Handa K, Ikeuchi K (2016) Thermal cracking of railway wheels: towards experimental validation. Tribol Int 94:409-420

10. Chichinadze A (1967) Calculation and investigation of external friction during braking. Moscow, USSR: Science 3 (in Russian)

11. Chichinadze A, Matveevski R, Braun E (1986) Materials in tribotechnics non-stationary processes. Moscow, USSR: Science 245 (in Russian)

12. Cho MH, Kim SJ, Kim D, Jang H (2005) Effects of ingredients on tribological characteristics of a brake lining: an experimental case study. Wear 258(11):1682-1687

13. Damme S, Nackenhorst U, Wetzel A, Zastrau BW (2003) On the numerical analysis of the wheel-rail system in rolling contact. In: Popp K, Schiehlen W (eds) System dynamics and long-term behaviour of railway vehicles, track and subgrade. Springer, Berlin, pp 155-174

14. Day A, Tirovic M, Newcomb T (1991) Thermal effects and pressure distributions in brakes. Proc Inst Mech Eng D J Automob Eng 205(3):199-205

15. de Vos P (2016) Noise in Europe: state of the art report. Technical report, Union Internationale des Chemins de fer (France)

16. Desplanques Y, Roussette O, Degallaix G, Copin R, Berthier Y (2007) Analysis of tribological behaviour of pad-disc contact in railway braking. Part 1: laboratory test development, compromises between actual and simulated tribological triplets. Wear 262(5):582-591

17. Dufrénoy P, Weichert D (1995) Prediction of railway disc brake temperatures taking the bearing surface variations into account. Proc Inst Mech Eng F J Rail Rapid Transit 209(2):67-76

18. Dufrénoy P, Weichert D (2003) A thermomechanical model for the analysis of disc brake fracture mechanisms. J Therm Stress 26(8):815-828
19. Dunaevsky V (1991) Prediction of railroad friction braking temperatures: prediction of average bulk and average surface temperatures of railroad wheels and brake discs. Tribol Trans 34(3):343-352

20. Esmaeili A, Walia MS, Handa K, Ikeuchi K, Ekh M, Vernersson T, Ahlström J (2017) A methodology to predict thermomechanical cracking of railway wheel treads: from experiments to numerical predictions. Int J Fatigue 105:71-85

21. Ghadimi B, Kowsary F, Khorami M (2013a) Thermal analysis of locomotive wheel-mounted brake disc. Appl Therm Eng 51(1):948-952

22. Ghadimi B, Sajedi R, Kowsary F (2013b) 3D investigation of thermal stresses in a locomotive ventilated brake disc based on a conjugate thermo-fluid coupling boundary conditions. Int J Heat Mass Transf 49:104-109

23. Ginsburg AG, Romashko AM, Titarenko VF (1974) Calculation of temperature regime of the railway disc brake. Moscow, USSR: Science Calculation and Simulation of Working Mode of a Brake and Friction Devices, pp 21-25

24. Gopal P, Dharani LR, Blum FD (1994) Fade and wear characteristics of a glass-fiber-reinforced phenolic friction material. Wear 174(1-2):119-127

25. Grzes P (2017) Determination of the maximum temperature at single braking from the FE solution of heat dynamics of friction and wear system of equations. Numer Heat Transf A Appl 71(7):737-753

26. Grzes P, Oliferuk W, Adamowicz A, Kochanowski K, Wasilewski P, Yevtushenko A (2016) The numerical-experimental scheme for the analysis of temperature field in a pad-disc braking system of a railway vehicle at single braking. Int $\mathrm{J}$ Heat Mass Transf 75:1-6

27. Gupta V, Hahn G, Bastias P, Rubin C (1996) Calculations of the frictional heating of a locomotive wheel attending rolling plus sliding. Wear 191(1-2):237-241

28. Heutschi K, Bühlmann E, Oertli J (2016) Options for reducing noise from roads and railway lines. Transp Res Part A Policy Pract 94:308-322

29. Jang H, Ko K, Kim S, Basch R, Fash J (2004) The effect of metal fibers on the friction performance of automotive brake friction materials. Wear 256(3):406-414

30. Jian Q, Shui Y (2017) Numerical and experimental analysis of transient temperature field of ventilated disc brake under the condition of hard braking. Int J Therm Sci 122:115-123

31. Kim DJ, Lee YM, Park JS, Seok CS (2008) Thermal stress analysis for a disk brake of railway vehicles with consideration of the pressure distribution on a frictional surface. Mater Sci Eng A 483:456-459

32. Krupa M (2008) Influence of temperature on value of friction coefficient in friction brakes, scientific papers of silesian university of technology. Transport 64:151-157

33. Kuciej M (2011) Investigation of the temperature field induced in the process of friction of a composite pad and a homogeneous disc. Int Commun Heat Mass 38(1):16-24

34. Li Z, Han J, Yang Z, Pan L (2014) The effect of braking energy on the fatigue crack propagation in railway brake discs. Eng Fail Anal 44:272-284

35. Milošević MS, Stamenković DS, Milojević AP, Tomić MM (2012) Modeling thermal effects in braking systems of railway vehicles. Therm Sci 16(Suppl. 2):515-526

36. Missori S, Sili A (1988) Optimizing proportions of railway brake discs by temperature transients evaluation. Proc Inst Mech Eng Transp Eng 202(2):91-99

37. Petereson M (2002) Two-dimensional finite element simulation of the thermal problem at railway block braking. Proc Inst Mech Eng C J Mech Eng Sci 216(3):259-273 
38. Petersson M, Vernersson T (2002) Noise-related roughness on tread braked railway wheels-experimental measurements and numerical simulations. Wear 253(1):301-307

39. Piechowiak T (2012) Hamulce pojazdów szynowych. Wydawnictwo Politechniki Poznańskiej (in Polish)

40. Qi HS, Day AJ (2007) Investigation of disc/pad interface temperatures in friction braking. Wear 262(5):505-513

41. Rhee SK (1974) Friction coefficient of automotive friction materials-its sensitivity to load, speed, and temperature. Technical report, SAE technical paper

42. Shorowordi K, Haseeb A, Celis JP (2004) Velocity effects on the wear, friction and tribochemistry of aluminum MMC sliding against phenolic brake pad. Wear 256(11):1176-1181

43. Suresh Babu A, Siva Prasad N (2009) Coupled field finite element analysis of railway block brakes. Proc Inst Mech Eng F J Rail Rapid Transit 223(4):345-352

44. Teimourimanesh S, Vernersson T, Lundén R, Blennow F, Meinel M (2014) Tread braking of railway wheels-temperatures generated by a metro train. Proc Inst Mech Eng F J Rail Rapid Transit 228(2):210-221

45. Teimourimanesh S, Vernersson T, Lundén R (2016) Thermal capacity of tread-braked railway wheels. Part 1: modelling. Proc Inst Mech Eng F J Rail Rapid Transit 230(3):784-797

46. Thuresson D (2004) Influence of material properties on sliding contact braking applications. Wear 257(5):451-460

47. Tirovic M (1998) Development of a wheel mounted disc brake for a high-speed train. Proc Inst Mech Eng F J Rail Rapid Transit 212(2):113-121

48. Union Internationale des Chemins de fer (2010) UIC Leaflet 541-4, Brakes-brakes with composite brake blocks-general conditions for certification of composite brake blocks, 4th edn. Union Internationale des Chemins de fer, Paris

49. Vernersson $T$ (1999) Thermally induced roughness of tread braked railway wheels. Part 2: modelling and field measurements. Wear 236(1):106-116

50. Vernersson T (2007a) Temperatures at railway tread braking. Part 1: modelling. Proc Inst Mech Eng F J Rail Rapid Transit 221(2):167-182
51. Vernersson $\mathrm{T}$ (2007b) Temperatures at railway tread braking. Part 2: calibration and numerical examples. Proc Inst Mech Eng F J Rail Rapid Transit 221(4):429-441

52. Voldřich J, Morávka Š, Študent J (2006) Transient temperature field in intermittent sliding contact at temperature dependent coefficient of friction. In: Proceedings of the 22nd conference computational mechanics, pp 697-704

53. Wasilewski P, Bułhak J (2017) Model numeryczny oraz badanie eksperymentalne pól temperatury podczas hamowania długotrwałego w układzie koło kolejowe-kompozytowa wstawka hamulcowa. Prace Naukowe Politechniki Warszawskiej Transport, pp 191-201 (in Polish)

54. Wasilewski P, Grzes P (2016) Numerical model and experimental study of temperature fields in a single application of railway tread brake. Proc EuroBrake 2016:1-10

55. Wu S, Zhang S, Xu Z (2016) Thermal crack growth-based fatigue life prediction due to braking for a high-speed railway brake disc. Int J Fatigue 87:359-369

56. Yevtushenko A, Grzes P (2012) Axisymmetric FEA of temperature in a $\mathrm{pad} / \mathrm{disc}$ brake system at temperature-dependent coefficients of friction and wear. Int Commun Heat Mass 39(8):1045-1053

57. Yevtushenko A, Grzes P (2016) Mutual influence of the sliding velocity and temperature in frictional heating of the thermally nonlinear disc brake. Int J Therm Sci 102:254-262

58. Yevtushenko A, Kuciej M (2010) Temperature and thermal stresses in a pad/disc during braking. Appl Therm Eng 30(4):354-359

59. Yevtushenko A, Adamowicz A, Grzes P (2013) Three-dimensional FE model for the calculation of temperature of a disc brake at temperature-dependent coefficients of friction. Int Commun Heat Mass 42:18-24

60. Yevtushenko A, Kuciej M, Grzes P, Wasilewski P (2017) Temperature in the railway disc brake at a repetitive short-term mode of braking. Int Commun Heat Mass 84:102-109

61. Ying S, Yupeng Y (2017) Temperature field analysis of pin-ondisk sliding friction test. Int J Heat Mass Transf 107:339-346 